\title{
THE FORMATION OF GEODES WITH REMARKS ON THE SILICIFICATION OF FOSSILS.
}

\author{
By Ray S. Bassler, \\ Curator, Division of Invertebrate Paleontology, U. S. National Museum.
}

Spherical, or irregular spheroidal, concretion-like masses, hollow and lined with crystals pointing inwardly, are known to geologists as geodes. Externally the similarity of these objects to concretions is so great that breaking is often required to determine their true nature. In matter of origin, there is little, if any, relation between the two. Geodic cavities are common in all kinds of rocks. Amygdaloidal cavities in igneous rocks are sometimes lined with crystals, thus giving rise to rounded masses coming within the above definition. Openings in veins of ore likewise may be lined with crystalline matter, and the term geode is sometimes applied even though the resulting object is far from spherical in shape. More often, however, these structures are found in sedimentary rocks, limestones and shales being particularly favored, but the general method of formation ascribed to them, namely that of the deposition of crystals from some mineral solution upon the walls of a cavity, is the same in all instances. Several limestone and shale formations have been so prolific of geodes that they are well known in geologic literature under such names as geodiferous limestone or the geode beds. Thus the geodes in the Niagara (Lockport) limestone, particularly at Lockport and Rochester, New York, early gave the name geodiferous limestone to the formation. These geodes are simply crystal-lined cavities, often of considerable size and number, scattered through the rock. The cavities owe their existence in many cases to the removal by solution of fossils; again they are simply fractures in the strata which become enlarged by the expanding force of crystallization. The material in these particular geodes is usually dolomite or gypsum, and the individual crystals are often large enough to make handsome mineralogical specimens. Some of the more striking materials found in these Niagara geodes are masses of silvery selenite, crystalline anhydrite, and crystals of amber-colored calcite and of pinkish dolomite. Similar occurrences of geodes in other limestones 
are well known and the specimen figured on Plate XVIII may be taken as an illustration of this particular phase of the subject.

In the first instance mentioned, the original cavity in the rock may have been left by the removal of a fossil by solution, but just as frequently the fossil itself furnishes the cavity. Figs. 3 to 8 on Plate XIX are from photographs of some common Upper Ordovician fossils well illustrating this occurrence. The large brachiopod, Platystrophia lynx (figs. 3 and 5), was evidently buried without being filled with mud or other materials. Its hollow interior then afforded an excellent place for the deposition of crystalline material. Only a portion of the interior of the smaller brachiopod, Rhynchotrema capax, figured on the same plate (figs. 6-8), was left unfilled with clay, and a correspondingly small geode resulted. What may be called a compound or, better, multiplex geode, results from the deposition of crystals in the hollow chambers of cephalopods. The Orthoceras, figured on Plate XIX, is an example of this on a small scale, but larger specimens are not infrequent. In this group of animals the shell, when intact, is less likely to become filled with clay, since the only means of ingress to the interior of the camerated portion is through the breakage of the walls of the camerae or of the siphuncle. No resistance is offered to the passage of water through the empty shell, and, as a result, almost every cephalopod in certain strata can be rated also as a geode. In all of this second group of geodes the crystalline material is calcite, usually in the form of dogtooth spar. The most striking and best-known geodes, however, are siliceous, and it is to this class that the writer wishes to call special attention. The examples referred to previously, as well as those that follow, are of such common occurrence that the facts here presented must have been noted by many observers. It was therefore with some hesitancy that the present paper was undertaken. A search of the literature, however, revealed little published information upon the subject. Doubtless references to geodes and geodization exist, but they are, apparently, as in the case of Professor Shaler's work referred to below, hidden under other titles.

Among the many problems of silicification the one of most interest to the paleontologist is unquestionably that bearing upon the replacement of fossils. Shells and other fossil forms entirely replaced by silica are of common occurrence in the cherty or siliceous débris resulting from the waste of limestones. These siliceous pseudomorphs, as they are called, often preserve the original shape and markings of the fossil form so perfectly that the peculiar interest of such a process to the paleontologist is obvious. Indeed, some very interesting faunas of geological time would be practically unknown if it had been necessary to work out the individual species from the hard, refractory limestone containing them. As an example of this, the 
many fine cystids and crinoids of the Curdsville formation in the central Kentucky Ordovician would never be known were it not for this replacement of these fossils by silica, nor would the hundreds of species of exquisitely preserved bryozoa, ostracods, corals, and other fossils from the Devonian strata at the celebrated Falls of the Ohio locality be available for study and comparison with specimens from less favorable localities. This phase of silicification has been explained by most writers as due to a replacement of the original calcareous material of the fossil by silica at the time of deposition. Under this view, the fossil shell, for example, is replaced by silica either on the ocean bottom at the time of deposition or shortly thereafter. In the case of a limestone then, the fossil would be simply a siliceous shell embedded in a calcareous groundmass. When in the course of weathering the limestone is dissolved away, the insoluble siliceous shells would then be left behind.

A few observers have noted that the limestone yielding such siliceous pseudomorphs upon weathering contains, in the unweathered state, only calcareous fossils. They have also observed that, as the weathering of the fossiliferous limestone proceeds, the fossils are replaced by silica and consequently are not carried away in solution as in the case of the matrix itself. In support of this view, the surface of a fossiliferous limestone layer is often seen sprinkled with fossils of which the portion still embedded in the limestone is calcareous and the exposed parts are siliceous. With this view the time of the silicification is necessarily assumed as very recent, in fact, as going on at the present time. The writer has had many opportunities to study and collect in areas where such silicification has occurred, and all of the facts observed have been in support of the latter idea. The object of this paper is not, however, to discuss this particular form of silicification, and the preceding remarks upon this recent replacement by silica are introduced only on account of their bearing upon the problem of the formation of siliceous geodes.

The best known siliceous geodes come from the Keokuk geode bed, which consists of blue shale and thin limestone 30 to 35 feet thick, particularly well shown at Keokuk, Iowa, and Warsaw, Illinois. The name of Amos H. Worthen will always be associated with these geodes, since years ago he distributed many barrels full of good specimens to the leading scientific men and institutions of this country and Europe. Mr. Worthen's localities are, therefore, best known to the scientific world, and the Keokuk geode bed is even better known than the geodiferous Niagara limestone of New York. The Keokuk geodes vary in size from that of a pea, or even less, up to rounded masses 2 feet in diameter. Quartz is the predominating crystalline material, but agate and crystals of calcite and dolomite are often accessory constituents. Such metallic minerals as millerite, in the form of hairlike needles or tufts of needles, sphalerite, and pyrite, are likewise 
found lining the cavities. Dana, in his Manual of Geology, says these geodes have been supposed to occupy the center of fossil sponges that were at some time hollowed out by siliceous solutions and then lined with crystals by deposition from the same or some other mineral solution. The writer has been unable to secure a full set of geodes from the Keokuk bed to illustrate their method of formation, but the specimens figured on the plates here presented are from shales and thin limestones of a horizon in Kentucky not strictly equivalent but similar in geological conditions.

These geodiferous shales and thin limestones belong to the Knobstone division of the lower Carboniferous or Mississippian period. Their strata cap the rounded hills of Indiana and Kentucky, encircling that portion of these two States immediately underlaid by Devonian and Silurian rocks. Southern Indiana, in the vicinity of New Albany, and the "Knob" region of Kentucky, extending south

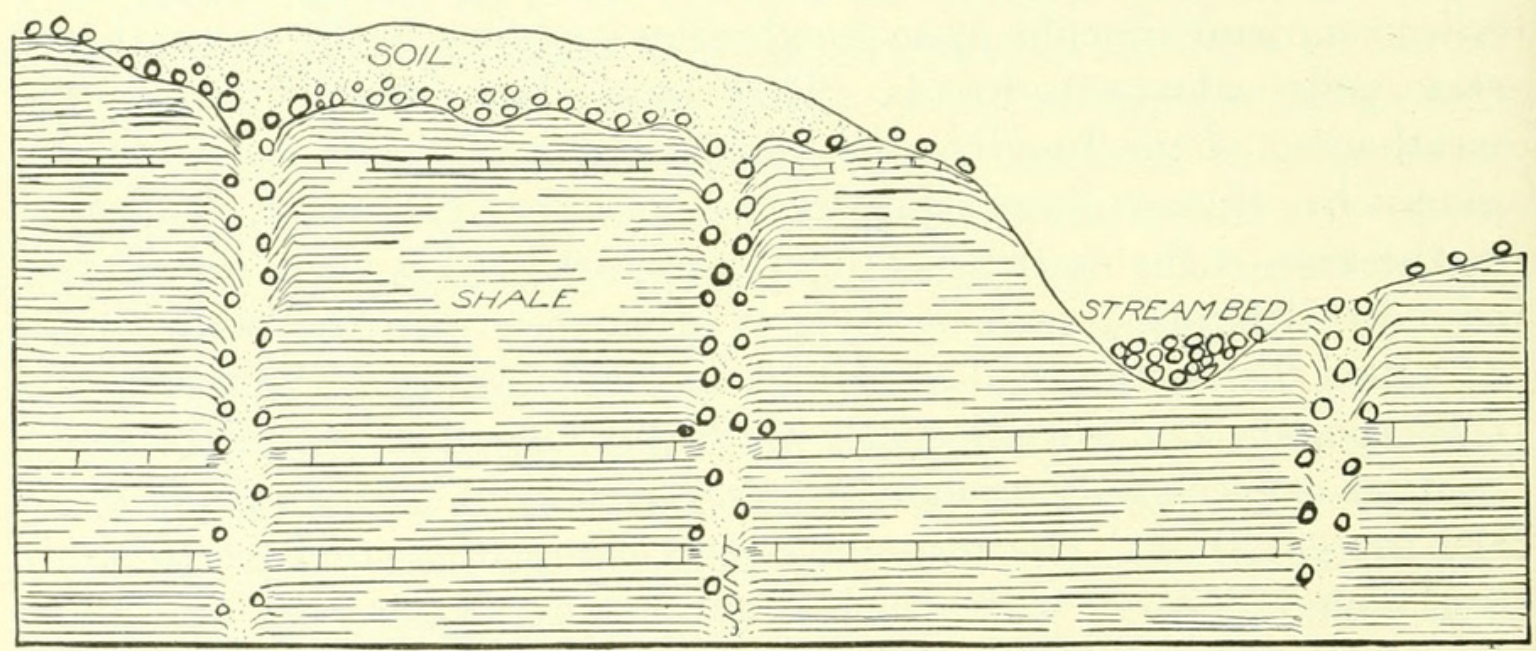

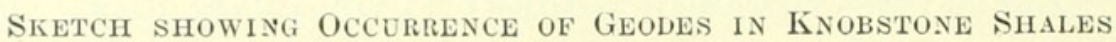

and then southeast of Louisville, give many exposures of the Knobstone group. Button Mold Knob, several miles south of Louisville and just opposite St. Jacobs Park of that city, is a celebrated locality for Knobstone fossils, and here the writer made most of his collections and observations. The geodes described in this paper from Button Mold Knob occurred in the lowest division of the Knobstone, a series of blue shale termed the New Providence shale. These strata are so compact that water can not readily pass through them. A few thin, ferruginous limestone layers are interbedded with the shale, but they are so infrequent as to have little effect upon the porosity of the strata. The rainfall upon these shales is, therefore, carried away almost entirely by surface drainage, and in the case of level areas underlaid by the shale, a damp, unproductive clay soil is the result of this imperviousness to water. Still, these shales are often crowded with geodes, objects which require the presence of water for their formation. This apparent association of many geodes and no water 
led to a study of the local conditions, with the result that the geodes were found to occur only in zones or areas reached by surface waters. Usually the geodes were lying on the surface itself, free or partially covered by the soil, and digging in the compact shale immediately beneath them would reveal no trace of other specimens. In other cases they were apparently buried in the shale, but, in every instance of this kind, closer examination showed these examples to lie on the edge or very close to joint planes or rifts in the strata through which water had easy access. The beds of streams heading in the Knobs are often crowded with geodes washed down from the higher strata. A sketch of these conditions of occurrence would, therefore, be something like that shown on the preceding page.

Having noted the occurrence of geodes, at least in these particular strata, it is next in order to inquire into their method of formation. To determine this point, the many specimens from the Knobstone group are here employed, although examples from other geodebearing horizons, such as the Upper Niagaran shales of West Tennessee, could be used. At this point it seems best for the present discussion to insert some observations by the late Prof. N. S. Shaler. These are incorporated in an article entitled Formation of Dikes and Veins, ${ }^{a}$ from which title one would never suppose that a discussion of geodes was included. The writer is indebted to Prof. J. C. Branner for calling attention to this article.

Some light on the foregoing question [the formation of dikes and veins] appears to be afforded by observations which may be readily made on the formation of geodes. As is well known, these bodies in their typical form are spheroidal masses, usually of quartz, which are formed essentially in the manner of veins. They may, indeed, be termed globular deposits in this class; in fact, by extending the inquiry over a large field $I$ have been able to trace a tolerably complete series of forms from spherical geodes to ordinary fissure veins, a series sufficiently without breaks to warrant the assumption that all these bodies belong in one category. A study of these geodes as they occur in Kentucky and elsewhere, especially in the shales of the sub-Carboniferous rock, has afforded me some interesting and instructive suggestions concerning the process of veinmaking which I will now briefly set forth.

Normal geodes are hollow spheroids and are generally found in shales. They clearly represent in most cases a segregation of silica, which has evidently taken place under conditions of no very great heat, brought about by deep burial beneath sediments or other sources of temperature. It is difficult in all cases to observe the circumstances of their origin, but in certain instructive instances this can be traced. It is there as follows: Where in a bed in which the conditions have permitted the formation of geodes the calyx of a crinoid occurs, the planes of junction of the several plates of which it is composed may become the seat of vein-building. As the process advances these plates are pushed apart and in course of time enwrapped by the silica until the original sphere may attain many times its original diameter and all trace of its origin lost to view, though it may be more or less clearly revealed by breaking the mass.

${ }^{a}$ Bull. Geol. Soc. Amer., X, 1899, pp. 253-262. 
In the process of enlargement which the geodes undergo they evidently provide the space for their storage by compressing the rock in which they are formed. In the rare instances where I have been able clearly to observe them in their original position they were evidently cramped against the country rock, the layers of which they had condensed and more or less deformed. Although when found upon the talus slopes or the soil these spheres usually contain no water in their central cavities, these spaces are filled with the fluid while they are forming and so long as they are deeply buried. There can be no doubt that this water is under a considerable though variable pressure.

The conditions of formation of spheroidal veins or geodes clearly indicate that an apparently solid mass of crystalline structure may be in effect easily permeated by vein-building waters, and this when the temperatures and pressures could not have been great. It is readily seen that the walls of these hollow spheres grow interstitially while at the same time the crystals projecting from the inner side of the shell grow toward the center. We therefore have to recognize the fact that the silex-bearing water penetrated through the dense wall. In many of these spherical veins we may note that the process of growth in the interior of the spheres has been from time to time interrupted and again resumed. These changes may be due to the variations in pressure to which the water in the cavities is necessarily subjected as the conditions of its passage through the geode-bearing zone are altered.

The most important information we obtain from the study of spherical veins or geodes is that no distinct fissures or rifts are required for the passage of rein-building waters through existing masses of lodes. It is true that the distances they traverse in these spherical lodes is limited to, at most, a few inches; but there is in these cases no other impulse than diffusive action to bring about the movement, while in an ordinary tabulate vein we may generally assume, in addition to the influence operating in bringing the dissolved materials into the geode, a pressure which impels the fluid upward. Thus, while it is not to be denied that many veins are prepared for by the formation of somewhat gaping fissures, and that these rents, after being more or less completely closed, are reopened by faulting on the plane of the deposit, such original or secondary spaces are not required for the development of a vein. The other point is that the pressure of the growing vein, which in the case of the geode is able so to condense the rock matter about it as to win room for the deposit, is likely to be eren more effective in the group of tabulate deposits in forcing the walls asunder.

While the purpose of Professor Shaler's remarks is primarily to show the relationship of geodes to veins, he has also pointed out some factors in the formation of the former. The writer must object to the following of his conclusions: First, that geodes are formed when deeply buried; second, that the water of formation is under a considerable though variable pressure; third, that the geodes are apparently solid masses of crystalline material, which may in effect be easily permeated by vein-building waters; fourth, that the silex bearing water necessarily penetrated through the dense wall; and fifth, that no distinct fissures or rifts are required for the passage of vein-building waters in the formation. Professor Shaler's statements upon the formation of these objects were based upon a study of specimens from the same horizon as those used by the writer, so that both sets of specimens must have had a common origin. The geodes in these Subcarboniferous, or Knobstone strata, are invariably siliceous and appar- 
ently always have a fossil as their basis of formation. Under the discussion of mineral veins, Professor Branner, in his Syllabus of Elementary Geology (p. 226), cites geodes as examples of enlargements of fractures by the expansion due to the crystallization of minerals in the incipient crevice. On page 228 of the same work he figures crinoid stems broken asunder, describing the figures as "Geodes formed in the stem of a crinoid. The deposition of quartz began in the hollow stem which was finally broken asunder." As may be observed from later remarks, the observations of the writer agree with Professor Branner's explanation save in the place of deposition of the silica. The subject of the force of growing crystals has been discussed by Merrill in $1895^{a}$ and by Becker and Day in $1905 .^{b}$

The majority of geodes in the Knobstone group may be traced directly or indirectly to a crinoidal origin for the simple reason that these strata are often crowded with fragments of this class of organisms. Probably next in order as a geode maker is the common brachiopod Athyris lamellosa, but no class of fossil is exempt from replacement by silica when the proper conditions obtain. Fragments of crinoid columns particularly are so abundant that series showing the complete development of geodes are readily obtained. These crinoidal columns are made up of a series of segments or "buttons" pierced centrally by a rounded or five-sided hole or canal. Professoi Branner believed that the deposition of silica started in this canal and continued until the column was fractured by the expansive force of crystallization. This is a very reasonable assumption, but none of the many unfractured crinoid columns before the writer shows a trace of silica in the central canal. These crinoidal columns are particularly subject to fracturing in the shale because of this central canal. The shape of the canal, as well as the five-sided symmetry prevailing in the class, usually causes five longitudinal fractures to form when the crushing is direct (see Plate XX, figs. 2 and 3 ). If pressure is exerted obliquely upon the column, a slipping of the segments upon each other is likely to occur (Plate XX, fig. 4). although fracturing may also accompany this slipping (Plate XX, fig. 5). All of the geodes originating in crinoid columns can be traced back to such fractured stems, and, also, only such fractured specimens occupying a position of ready access to water shown in the sketch on page 136 were geodized. Numerous fragments similar to the originals of figs. 1-6 on Plate XX, can be dug up from the impervious shales and no signs of silicification observed, but in the water horizons almost all the fractured specimens show some trace of silica. It therefore seems apparent that the deposition of silica is

${ }^{a}$ On the formation of stalactites and gypsum incrustations in caves, Proc. U. S. Nat. Mus., XVII, pp. 77-81, pls. II-V.

$b$ The linear force of growing crystals, Proc. Washington Acad. Sci., VII, pp. $283-288$. 
not in regular cavities where the water can circulate freely, but along fracture lines in which capillary attraction is responsible for the penetration of the mineral bearing solutions. Complete series, in which these fractures are occupied by only a thread-like trace of silica up to the normal geode, showing no trace of crinoidal matter, have been seen, but the specimens illustrated on Plates XX and XXI were deemed sufficient for the purpose. Filling of a longitudinal and transverse fracture is shown in fig. 7 of Plate XX; fig. 8 illustrates three of the five silica-filled fractures of another column. In fig. 9 the mineral deposit in the five main fractures has exerted such a pressure that the intermediate crinoidal material has been broken into small fragments. Each of these minor fractures would have developed stringers of silica had the deposition continued. Such minute breaks are illustrated in figs. 6 and 13, the latter showing the siliceous deposition in a specimen fractured like the original of fig. 6 . In fig. 10 the regular arrangement of the silica along five prominent lines is obscured by replacement of side "veins," the original specimen being, apparently, similar to that shown in fig. 3. Figs. 11 and 12 illustrate specimens showing deposition along oblique as well as longitudinal fracture lines. In fig. 14 the mineral matter has been deposited most abundantly at the intersections of two sets of fractures, thus producing a botryoidal appearance in the resulting geodes. This botryoidal effect is more pronounced in figs. 3, 8, 9, 10, and 11 on Plate XXI, but the same origin is evident from the adhering crinoidal remains. Such specimens are usually hollow and lined with drusy quartz (figs. 5 and 7 ). The crust is often so thin that the geode itself may be crushed (fig. 12). In the final stage all trace of the crinoidal material is lost, although the original five fractures often determine the shape and indicate the origin of the geode. Occasionally the fragments of crinoidal matter between the ridges of silica are removed by solution and leave fluted masses of silica as in fig. 6. That the geodes of this particular geological horizon are not always confined to fossils for their growth, is evidenced by the fragment of crinoidal limestone figured on Plate XXI, fig. 14. Evidently two parallel fractures and a third at right angles have penetrated this specimen and the deposition of silica has followed. Except the last, all of the foregoing illustrations have been based on crinoid columns. In the case of the calyx of a crinoid, little or no fracturing is necessary to give rise to the deposition of silica, since the plate sutures furnish an excellent place for crystalline growth. This particular phase is sufficiently illustrated on Plates XIX and XXIV to require no further mention. Nor does it seem necessary to describe the various stages in geode growth starting from a brachiopod as Plates XXII and XXIII are deemed explanatory enough. As the arrangement of the fractures in crushed brachiopods is usually indefinite, the geodes resulting from this class are traced with more difficulty. It is, 
therefore, only when fragments of the original shell are retained, as in figs. 9 and 10 of Plate XXII, that no doubt as to the origin can exist. In these brachiopods it will be noted that the main fracture line is at right angles to and passes through the beak. From this line other fractures often radiate, so that in case of removal of the intervening calcareous shell matter a septarian like effect is produced (Plate XXIII, fig. 11).

In all of the specimens just described the deposition of silica in the fracture has been preceded by a complete silicification of the fossil itself, in the manner described on page 135. Sometimes this complete replacement of calcite by silica leaves a perfect representation of the fossil, but again silicification may destroy all the details of structure (Plate XXIV, fig. 5). Should the fossil when silicified present no fracture, no deposition of crystals preliminary to the formation of a geode occurs, but fractured silicified specimens are subject to geodization. The column figured on Plate XXIV (fig. 6) is completely silicified and small stringers of quartz occupy the fracture. Less frequently these two processes of silicification seem to occur simultaneously.

Returning to the suggestion in Dana's Manual of Geology that the Keokuk geodes are hollowed out sponges lined with crystals, it seems more reasonable, in view of the absence of such sponges in that formation and the presence of numerous specimens indicating the origin described above, that the latter is nearer the truth. Professor Shaler's idea that this class of geodes is formed when deeply buried is not in accord with the facts, at least as observed by the writer, nor does there appear to be any necessity for the water of formation to be under a considerable though variable pressure. Ordinary surface waters charged with silica seem to be sufficient. The other objections to Professor Shaler's views regarding the method employed by the silex-bearing waters to reach the interior of the geode are explained in tracing their origin to fractured fossils. The deposition of crystals on opposite sides of a fracture will always leave a space free to the passage of water, so that no necessity exists for this water of formation to penetrate the solid mass.

In conclusion, the best known geodes are free, rounded, siliceous, hollow masses lined internally with crystals, and occurring usually in shaly, fossiliferous strata. Fossils lying in the path of surface waters are subject to a complete replacement of their substance by silica; when crushed or fractured, fossils may have the breaks lined with a siliceous deposit. In the latter case, continued deposition and the expansive force of the crystals will result in a hollow, rounded mass, or geode, lined with inwardly pointing crystals and on the outside covered with remnants of the fossil. The chemical side of this subject is a problem which is not in the province of the present paper. 
Explanation of Plate XViII.

Fig. 1. A fragment of an ordinary siliceous geode from the Keokuk geode bed at Keokuk, Iowa.

2. Portion of a geodic cavity from North Park, Colorado. In this case a cavity in limestone is lined with crystals of calcite.

142 

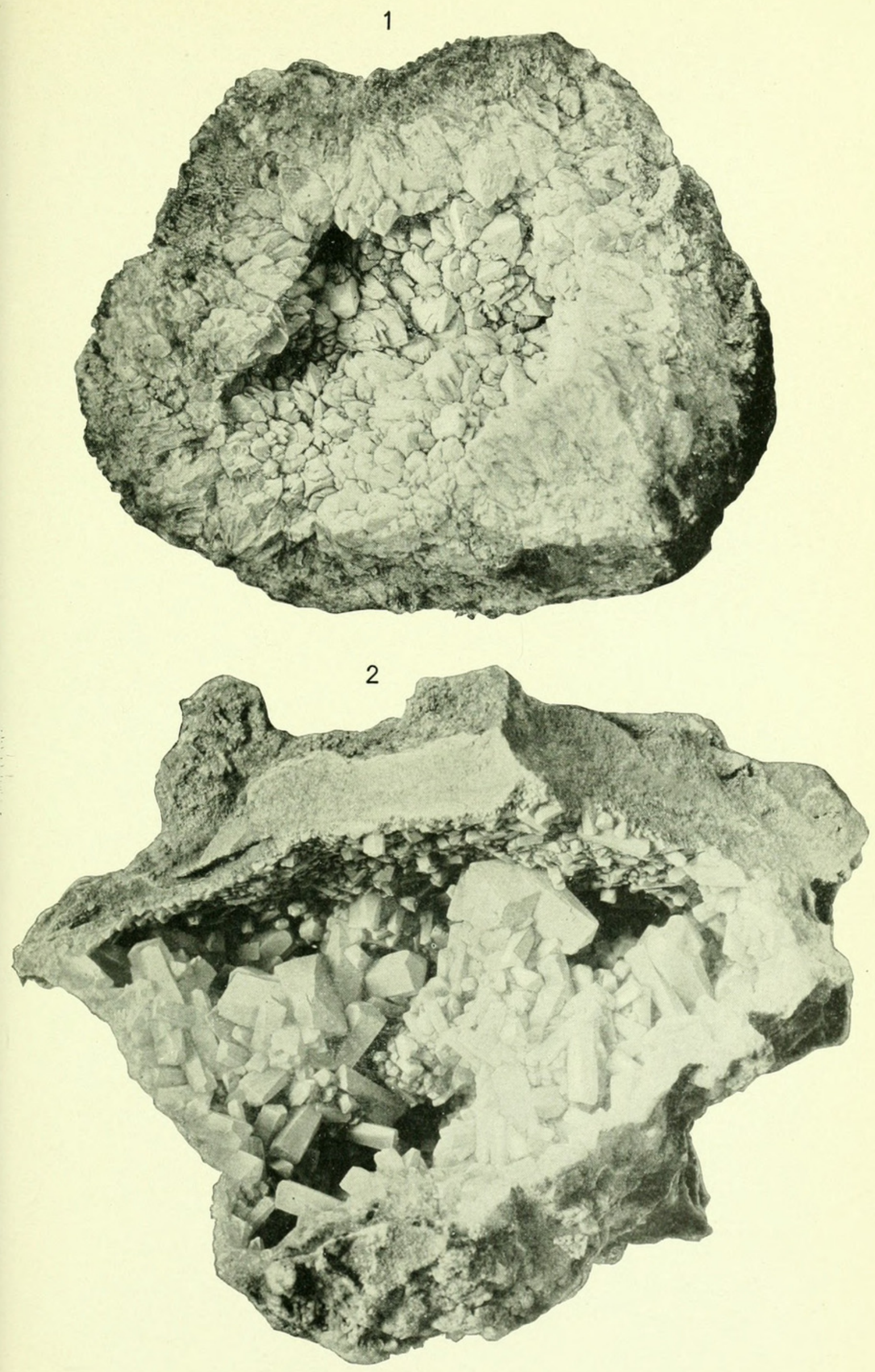

(1) A Siliceous Geode and (2) a Geodic CaVity.

FOR EXPLANATION OF PLATE SEE PAGE 142 




\section{Explanation of Plate Xix.}

All of the figures on this plate, except 3, 6, and 9, are slightly enlarged.

Fig. 1. A fragment of the cephalopod shell Orthoceras duseri broken through the middle and showing the chambers lined with dog tooth spar.

2. The wall of one of the crystal lined chambers viewed from above.

3,4 , and 5. Natural size view of the brachiopod Platystrophia lynx and enlarged views of its halves, showing the geode nature of the shell.

6,7 , and 8 . The brachiopod Rhynchotrema capax, natural size, and enlargements of its halves. In this case the geode occupies only a part of the shell, the remaining portion being filled with indurated clay.

The originals of figures 1 to 8 are from the Ordovician rocks of southwestern Ohio.

9. Basal view of a crinoid calyx, natural size, in which the deposition of silica in the plate sutures has not progressed far.

10. View of the cross-section of the original of fig. 7, Plate XX. The interior of this specimen is almost completely filled with quartz crystals. In this as well as in figs. 11 and 12, the dark colored material is of unchanged crinoidal calcite.

11 and 12. Transverse views of the original of fig. 8 , Plate $\mathrm{xx}$, and of another specimen when fractured. The five silica-filled fractures and the hollow central area are characteristic. 

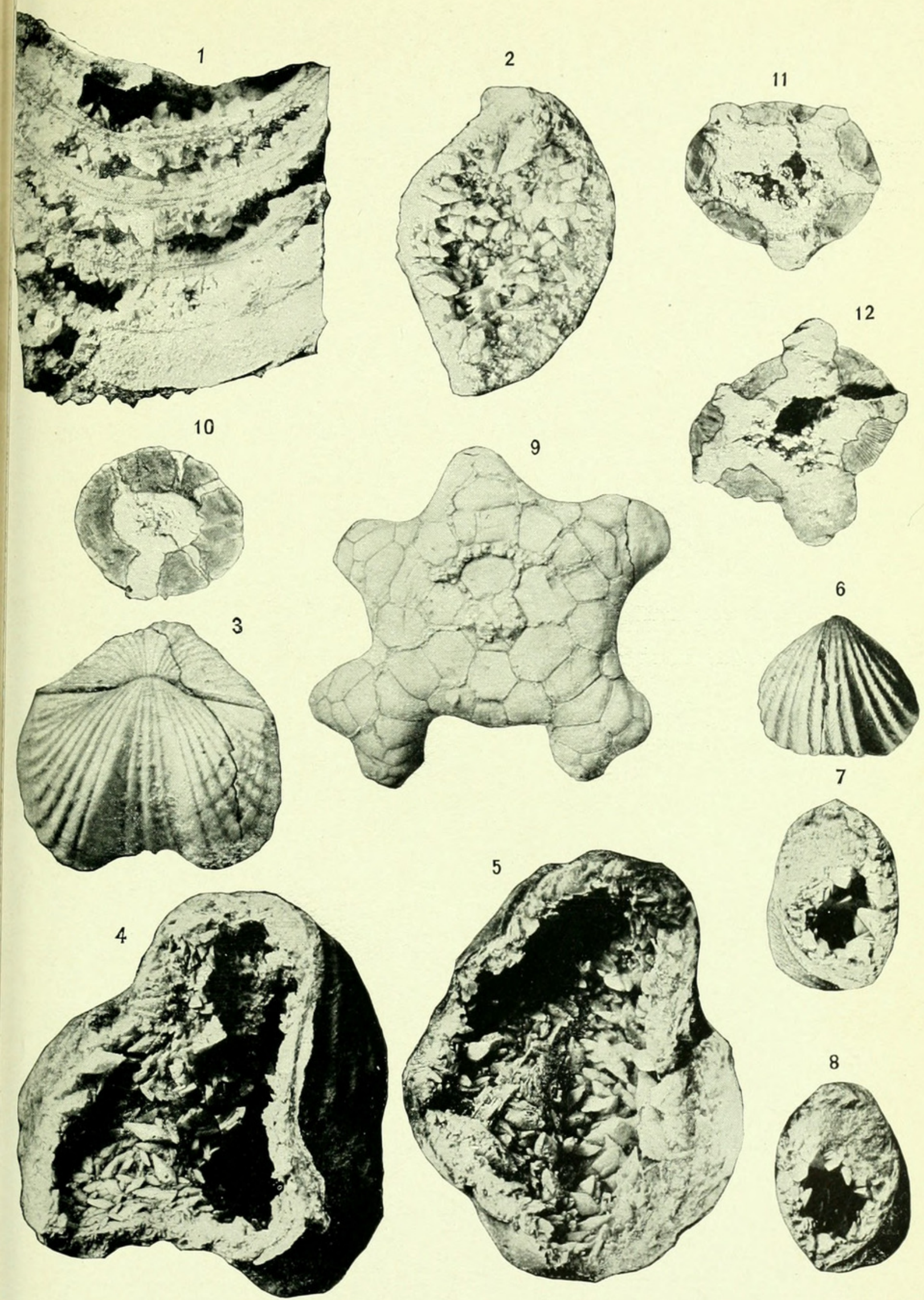

invertebrate fossils illustrating Formation of Geodes.

For explanation of PLATE SEe PAge 144.

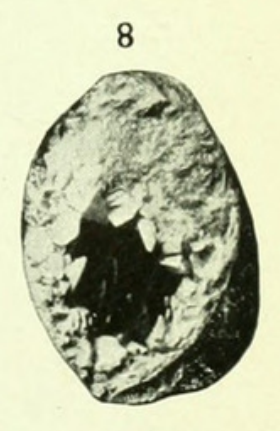



Proc. N. M. vol. $x \times x y-08-10$ 


\section{Explanation of Plate XX.}

All of the figures on this plate are $\times 1.5$ with the exception of $7-9$, and 11 , which are natural size. The specimens are from the Lower Knobstone shales at Button Mold Knob, Kentucky.

Fig. 1. View of two segments of a crinoid column illustrating the five sided central canal.

2 and 3 . Views of opposite sides of a crushed crinoid column. The principal longitudinal fractures correspond in number and arrangement with the pentagonal central canal shown in fig. 1.

4. Portion of a crinoid column in which the individual segments have been slightly pushed apart.

5. Another fragment illustrating slipping of the segments and longitudinal fracturing.

6. A crushed crinoid column with many small fractures as well as the principal longitudinal breaks.

7. A crinoid column with the principal longitudinal fracture, and the ends tain a smaller amount of silica.

8. Another crinoid column with the five main fractures and the ends filled with silica. In this specimen the individual segments of the column were not found apart previous to silicification and hence no transverse bands of silica have been deposited. Transverse views showing the interior of figs. 7 and 8 are given on Plate XIX.

9. A crinoid column in which a great amount of longitudinal fracturing has occurred. Only the five principal fractures corresponding to the pentameral symmetry of the organism are filled with distinct bands of silica, although the small breaks contain thread-like masses of this material.

10. A crinoid column with irregular fractures filled with silica.

11 and 12. Two fragments of crinoid columns which have suffered longitudinal fracturing as well as transverse slipping of the segments previous to the deposition of silica.

13. A crinoid column fractured in the manner of the original in fig. 6 and the spaces then filled with silica.

14. An obliquely crushed crinoidal column with the deposits of silica segregated at the junction of fracture so as to assume a botryoidal structure.

The originals of figs. 1 to 6 , inclusive, are calcareous specimens from the compact shales in which no silicification occurs. The remaining specimens, figs. 7 to 14 , were found either on the surface or in a zone of silicification. 

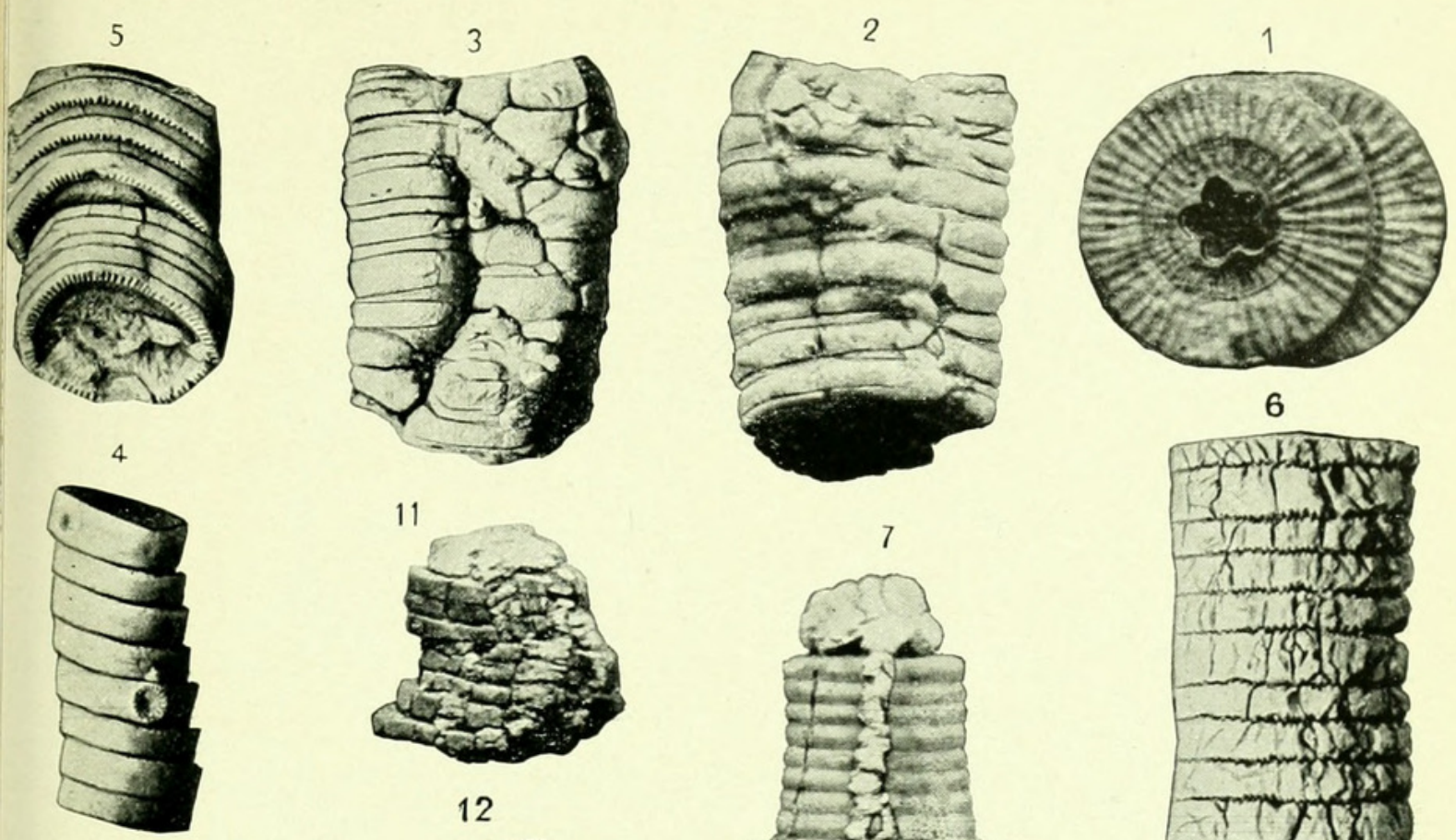

11
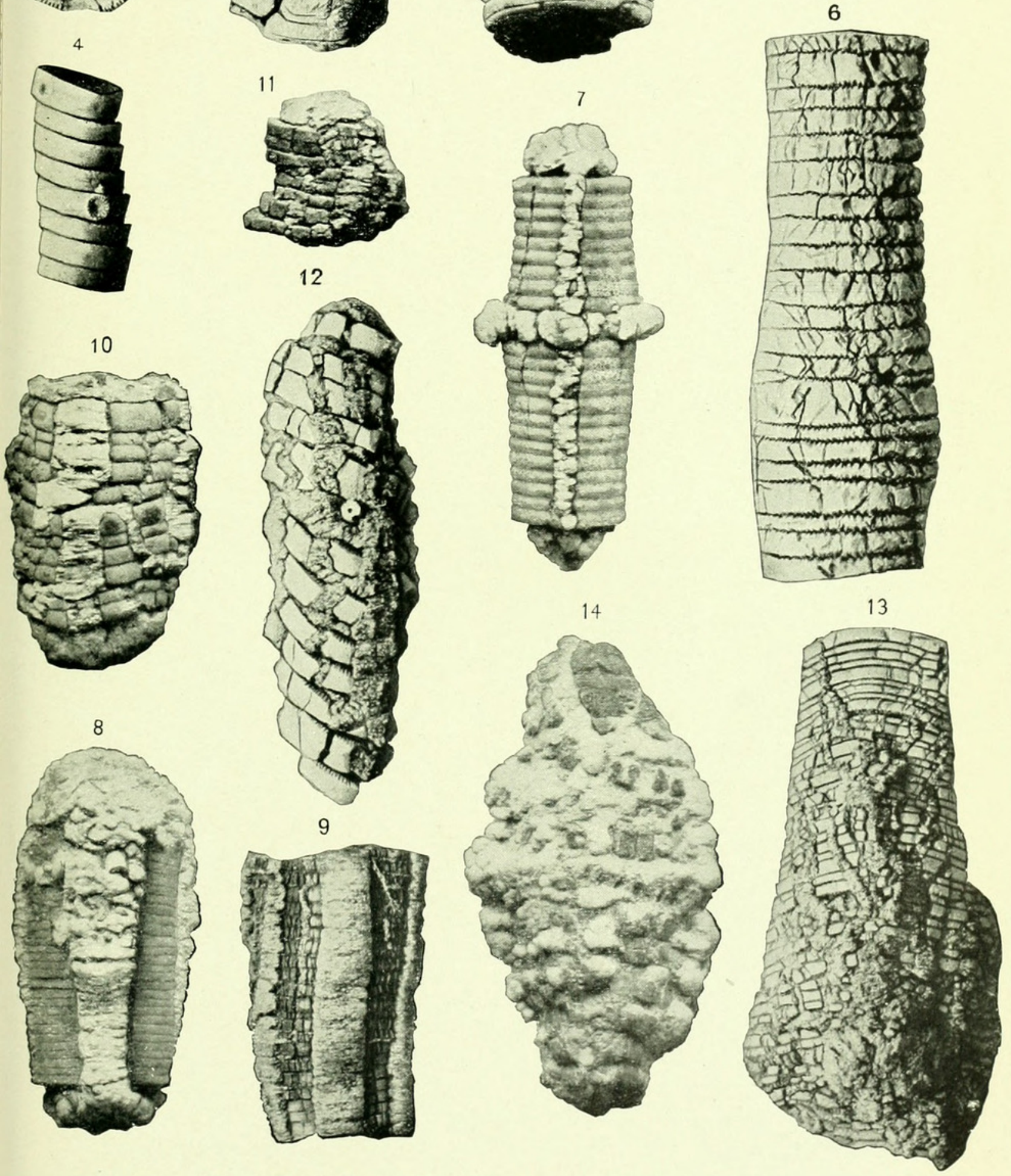

Crinoidal Remains illustrating Formation of Geodes.

For explanation of PLate see Page 146. 

. 
Figs. $1-3$, and $8-11$, are $\times 1 \frac{1}{2}$, while the rest are natural size. All of the specimens were collected in the Lower Knobstone shales at Button Mold Knob, Kentucky.

Figs. 1 and 2. A geode with a crinoid column às a basis.

3. A small geode with small fragments of the crinoid column still showing on its surface.

4. A larger example retaining little trace of crinoidal matter.

5. The interior of a specimen similar to fig. 3, lined with drusy quartz.

6. A geode similar to fig. 2 , with the crinoidal calcite removed.

7. Another geode derived from a much fractured crinoid column.

8 to 11. Four small geodes showing their derivation by deposition of silica in crinoid columns.

12 and 13. Top and side views of two small geodes whose formation from crinoid columns is apparent from their five-sided outlines.

14. A mass of crinoidal fragments showing silica replacing the larger fractures. 


\section{$2 \mathrm{BHL}$ Biodiversity Heritage Library}

Bassler, Ray S. 1908. "The formation of geodes with remarks on the silicification of fossils." Proceedings of the United States National Museum 35(1637), 133-154. https://doi.org/10.5479/si.00963801.35-1637.133.

View This Item Online: https://www.biodiversitylibrary.org/item/32327

DOI: https://doi.org/10.5479/si.00963801.35-1637.133

Permalink: $\underline{\text { https://www.biodiversitylibrary.org/partpdf/27573 }}$

\section{Holding Institution}

Smithsonian Libraries

\section{Sponsored by}

Smithsonian

\section{Copyright \& Reuse}

Copyright Status: NOT_IN_COPYRIGHT

This document was created from content at the Biodiversity Heritage Library, the world's largest open access digital library for biodiversity literature and archives. Visit BHL at https://www.biodiversitylibrary.org. 